\title{
Plant uptake of phosphorus from sparingly available P-sources as affected by Trichoderma asperellum T34
}

\author{
Ana M. García-López, Manuel Avilés and Antonio Delgado \\ Agroforestry Sciencie Department University of Seville. Ctra Utrera Km 1. 41013 Seville, Spain \\ e-mail: adelgado@us.es
}

\begin{abstract}
The contribution of Trichoderma asperellum T34 to the plant uptake of phosphorus (P) from sparingly phytoavailable forms such as insolublecalcium (Ca) phosphates and phytates was studied. Two experiments with cucumber (Cucumis sativus L.) on siliceous sand were performed involving two factors, namely: (i) P source, viz. $\mathrm{KH}_{2} \mathrm{PO}_{4}$, phytate (Ins6 P), and phosphate rock (PR), and (ii) inoculation with T34. Liquid pure cultures of T34 were also used. T34 increased the total content in $\mathrm{P}$ of cucumber roots irrespective of the particular $\mathrm{P}$ form and enhanced total $\mathrm{P}$ uptake by plants with P supplied as Ins6P or PR. The increased phytase activity observed with T34 contributes to explain its favourable influence on the uptake of P supplied as Ins6P. Solubilization of Ca phosphates from PR was favoured by the slightly acidifying effect and the increased organic anion concentration promoted by the fungus in the plant growth media. It can be concluded that T34 can improve P nutrition in plants grown on media containing phytates or insoluble $\mathrm{Ca}$ phosphates as dominant $\mathrm{P}$ forms.
\end{abstract}

Key words: phosphorus, Trichoderma, rhizosphere, Ca phosphates, phytase.

\section{Introduction}

The consequences of the depletion of $P$ resources have aroused increasing interest in recent years, especially after the rapid increase of phosphate rock prices in 2007 and 2008 (Cordell et al. 2009, Gilbert 2009). Efficient use of $\mathrm{P}$ can help to make agriculture sustainable in a scenario of increasing prices of fertilizers owing to the rapid depletion of available reserves (Cordell et al. 2009, Ryan et al. 2012). Also, unlocking residual P forms bound to soil is an essential stage towards a sustainable future for agriculture (Stutter et al. 2012).

Soil microorganisms can facilitate the mobilization of soil P through various mechanisms (Wang et al. 2012). Many rhizobacteria and fungi possess mechanisms to mobilize Fe, and hence Fe-bound $P$, including chelator release, acidification (Marschner et al. 2004, Lemanceau et al. 2009) and reduction processes (Sánchez-Alcalá et al. 2011). Acidification by plant growth-promoting bacteria facilitates uptake of $\mathrm{P}$ from poorly soluble -and hence largely unavailable- Ca phosphates by plants (Browne et al. 2009, Singh and Reddy 2011). Also, rhizosphere microflora is known to promote the hydrolysis of organic $P$ forms by releasing hydrolytic enzymes, which facilitates their use as $P$ sources by plants (Hariprasad and Niranjana 2009, Patel et al. 2010). The mobilization of P from poorly soluble Ca phosphates and stable organic forms such as phytates can be important in many environments, where both sparingly available P forms frequently account for most P present in soil (Celi et al. 2001, Saavedra et al. 2007). Increasing the acquisition of $P$ by plants from these residual soil $P$ forms by microbial inoculation can contribute to a more sustainable management of non-renewable $\mathrm{P}$ resources and to improve the productivity of $\mathrm{P}$-poor soils, which expand on one third of the agricultural land in the World (MacDonald et al. 2011).

Biological control agents can be effective in mobilising $\mathrm{P}$ in the rhizosphere, which warrants their use for integrated management of plant diseases and P supply to plants (Vassilev et al. 2006), thus contributing to a more sustainable agricultural production. The soil fungi Trichoderma spp. are efficient, widely used biological control agent (Howell 2003, Schuster and Schmoll 2010) that enhances nutrient uptake by plants (Yadav et al. 2009, de Santiago et al. 2013). In spite of the effects described by Altomare et al. (1999) or Rudresh et al. (2005), little information about contribution of Trichoderma to P uptake by plants is available. Although the positive contribution of P-mobilizing microorganisms to plant nutrition is well-known, evidences of mobilization from specific $P$ forms and mechanisms involved in this process are most often limited to pure cultures of microorganisms and rarely observed in plant growth studies (Singh and Reddy 2011, Wang et al. 2012). For accurate assessment of their use to improve plant nutrition, it is required: (i) more direct evidences of the effect of microorganisms on plant $P$ uptake from specific $\mathrm{P}$ forms present in soil, (ii) a deeper knowledge about mechanisms involved in P mobilization in plant growth media, and (iii) how these mechanisms interact with P-mobilizing mechanisms of plants. 
This work was undertaken in order to study the contribution of Trichoderma asperellum T34, an effective biocontrol agent (Segarra et al. 2007), to plant uptake of P from sparingly phytoavailable forms such as insoluble Ca phosphates and phytates by plants, and also to elucidate the mechanisms behind this potential effect in plant growth media with a view to facilitating the integrated use of the fungus in biocontrol and fertilization strategies.

\section{Materials and methods}

\section{Experimental setup}

Two sets of experiments were performed, namely: (i) cultivation of T34 in liquid media, in order to assess its Pmobilizing mechanisms and (ii) inoculation experiments with plants grown in artificial growth media to assess how T34 can contribute to $P$ nutrition of plants from different $P$ sources.

\section{Cultivation of T34 in liquid media}

Trichoderma asperellum T34 was cultivated in Czapek liquid media containing P from various sources in order to examine the potential enzyme production and acidification abilities of the fungus. The media contained sucrose $\left(30 \mathrm{~g} \mathrm{~L}^{-1}\right), \mathrm{NaNO}_{3}\left(2 \mathrm{~g} \mathrm{~L}^{-1}\right), \mathrm{MgSO}_{4}\left(0.1 \mathrm{~g} \mathrm{~L}^{-1}\right), \mathrm{KCl}\left(0.5 \mathrm{~g} \mathrm{~L}^{-1}\right)$ and FeSO $\cdot 7 \mathrm{H}_{2} \mathrm{O}\left(0.01 \mathrm{~g} \mathrm{~L}^{-1}\right)$, and had a pH of 7.8. A completely randomized experiment with 3 replications was performed by using an identical T34 inoculation rate (100 conidia $\mathrm{mL}^{-1}$ ) and a single factor ( $\mathrm{P}$ source) with 4 different treatments, namely: (i) phosphate applied as $\mathrm{KH}_{2} \mathrm{PO}_{4}$ at full strength of $0.23 \mathrm{~g} \mathrm{~L}^{-1} \mathrm{P}$, which is the usual concentration for this type of medium, (ii) $\mathrm{KH}_{2} \mathrm{PO}_{4}$ at $23 \mathrm{mg} \mathrm{L}^{-1}$ $\mathrm{P}\left(1 / 10\right.$ strength $\left.\mathrm{KH}_{2} \mathrm{PO}_{4}\right)$, (iii) ground $\left(<0.1 \mathrm{~mm}\right.$ ) phosphate rock ( $\mathrm{PR}$, essentially apatite) at $0.23 \mathrm{~g} \mathrm{~L}^{-1} \mathrm{P}$, and (iv) phytate (myo-inositol-6-hexakisphosphate Na salt, Ins6P) at $0.23 \mathrm{~g} \mathrm{~L}^{-1} \mathrm{P}$. The low $\mathrm{KH}_{2} \mathrm{PO}_{4}$ treatment $\left(23 \mathrm{mg} \mathrm{L}^{-1} \mathrm{P}\right)$ was included to study responses of T34 to suboptimal phosphate concentrations in solution that were greater than that expectable with an insoluble P source (RP). Cultivation runs were done in $250 \mathrm{~mL}$ glass flasks.

After 7 days of cultivation, the media were passed through a cellulose nitrate filter of $0.22 \mu \mathrm{m}$ pore size and used to determine fungal biomass, enzyme activities in solution, $\mathrm{pH}$, molybdate reactive $\mathrm{P}(\mathrm{MRP})$ according to Murphy and Riley (1962), and the concentration of major organic anions produced (particularly those capable of mobilizing Fe and $\mathrm{P}$ such as oxalic and citric).

\section{Inoculation experiments with plants}

Experiments with cucumber plants (Cucumis sativus L. cv Tropico) were performed by using an artificial growth medium consisting of siliceous sand previously sieved through 0.5 and $1 \mathrm{~mm}$ mesh in order to ensure adequate aeration and hydraulic conductivity. The sand was washed several times with $0.2 \mathrm{M} \mathrm{Na}_{2} \mathrm{CO}_{3}$ to improve dispersion and remove impurities. The source of Fe in the growth media was ferrihydrite, which was supplied by coating part of the siliceous sand with this oxide according to Rahmatullah and Torrent (2000). The concentration of Fe bound to ferrihydrite in the growth media, estimated as citrate-ascorbate extractable Fe, was $200 \mathrm{mg} \mathrm{kg}^{-1}$ Fe medium. The $\mathrm{pH}$ of the media was 8 and the electrical conductivity (EC) in all (1:5 medium:water extract) lower than $100 \mu \mathrm{S} \mathrm{m}$.

Two different experiments were conducted under exactly the same plant growth conditions by using a completely randomized design with five replications (one pot per replication and one plant per pot) and two factors, namely: P source, with three different treatments $\left(\mathrm{KH}_{2} \mathrm{PO}_{4}\right.$, Ins6P and PR $\left.[<0.1] \mathrm{mm}\right)$, and T34 (tests with and without inoculation [control]).

Phosphorus from $\mathrm{KH}_{2} \mathrm{PO}_{4}$ and Ins6P was supplied in the form of compounds adsorbed on Fe oxides covering part of the siliceous sand in order to imitate the major fractions of these $P$ forms in soils which are usually bound to Fe oxides as dominant sorbent surfaces, whereas PR was carefully mixed with the growth media before transplanting. This growth medium was intended to mimic the dynamics of two major soil $P$ forms not readily available, namely: sparingly soluble Ca phosphates and phytates (Saavedra and Delgado 2005). The P rate used in all the cases was $6.4 \mathrm{mg}$ of $\mathrm{P}$ per kg of growth medium, equivalent to $2.56 \mathrm{mg} \mathrm{pot}^{-1} \mathrm{P}$ (viz., 2-3 times the amount of $\mathrm{P}$ expected to be absorbed by each plant). Phosphate and Ins6P were adsorbed on siliceous sand coated with Fe oxides by immersing $1 \mathrm{~kg}$ of sand in $1.5 \mathrm{~L}$ of the same nutrient solution used in the experiment, which contained 5.25 and $6 \mathrm{mg} \mathrm{L}^{-1} \mathrm{P}$ as $\mathrm{KH}_{2} \mathrm{PO}_{4}$ and Ins6P sodium salt, respectively. Phosphorus concentration in surrounding 
solution was determined daily and nutrient solution with $\mathrm{P}$ replaced by a new one with the same $\mathrm{P}$ forms and concentration until the desired adsorbed $\mathrm{P}$ amount was obtained. After adsorption, $\mathrm{P}$ concentration in equilibrium with siliceous sand coated with Fe oxide was $1.5 \mathrm{mg} \mathrm{L}^{-1} \mathrm{P}$ and $3 \mu \mathrm{g} \mathrm{L} \mathrm{L}^{-1} \mathrm{P}$ for $\mathrm{KH}_{2} \mathrm{PO}_{4}$ and Ins6P, respectively. Then, to check that amounts of sorbed $\mathrm{P}$ were those estimated, and to know the dominant forms in which $\mathrm{P}$ was retained in the medium, a sequential extraction with $0.1 \mathrm{M} \mathrm{NaOH}+1 \mathrm{M} \mathrm{NaCl}$ and $1 \mathrm{M} \mathrm{HCl}$ was performed. The first extraction step, which was intended to desorb P from Fe oxides, recovered $53 \%$ of inorganic phosphate and $45 \%$ of Ins6P, the second step released the remaining sorbed $\mathrm{P}$-mostly precipitated $\mathrm{P}$, which indicates that a substantial fraction of the inorganic phosphate or InsP6 supplied precipitated as Ca salts (Ca provided by nutrient solution) as it can be expected in soils with similar pH (e.g. Lindsay (1979) for inorganic phosphate, or Celi et al. (2001) for InsP6). Phosphorus in nutrient solution used to adsorb P on Fe oxides and in the extracts of sequential extraction were determined colorimetrically (Murphy and Riley 1962), following persulphate digestion (Díaz-Espejo et al. 1999) in the case of those samples treated with Ins6P.

Inoculation with T34 was carried out by immersing roots in a water suspension containing $10^{3}$ conidia $\mathrm{mL}^{-1}$ before transplanting (de Santiago et al. 2009), followed by addition of $10^{4}$ conidia $\mathrm{g}^{-1}$ medium after transplanting. The microorganisms were supplied in $20 \mathrm{~mL}$ of a water suspension containing $2 \cdot 10^{5}$ conidia $\mathrm{mL}^{-1}$ and prepared according to Segarra et al. (2007), a micropipette was used to apply the conidia at four points around each plant.

Seeds were sown in $35 \mathrm{~mL}$ polyvinyl multipots that were filled with perlite and irrigated with de-ionized water. After 28 days, plants were transplanted in the growth medium and allowed to grow for a further 26 days. Each pot ( $350 \mathrm{~mL}, 5.5 \mathrm{~cm}$ diameter, $15 \mathrm{~cm}$ high polystyrene cylinder) was filled with $400 \mathrm{~g}$ of siliceous sand ( $80 \mathrm{~g}$ with adsorbed Fe oxides) and used to grow a single plant. The experiment was conducted in a growth chamber with a photoperiod of $14 \mathrm{~h}$, a $25 / 23{ }^{\circ} \mathrm{C}$ day/night temperature, $65 \% \mathrm{RH}$ and $22 \mathrm{w} \mathrm{m}^{-2}$ light intensity. Pots were irrigated daily with of a Hoagland type nutrient solution without $\mathrm{P}$ and Fe. The total volume of solution applied per pot was $300 \mathrm{~mL}$, and composition of the nutrient solution was (all concentrations in $\left.\mathrm{mmol} \mathrm{L}^{-1}\right): \mathrm{MgSO}_{4}(2), \mathrm{Ca}\left(\mathrm{NO}_{3}\right)_{2}$ (5), $\mathrm{KNO}_{3}(5), \mathrm{KCl}(0.05), \mathrm{H}_{3} \mathrm{BO}_{3}(0.024), \mathrm{MnCl}_{2}(0.0023), \mathrm{CuSO}_{4}(0.0005), \mathrm{ZnSO}_{4}(0.002)$ and $\mathrm{H}_{2} \mathrm{MoO}_{4}(0.0005)$. The $\mathrm{pH}$ of the nutrient solution was 6 .

After the experiments, plant dry matter (DM) in shoots and roots was measured, and P and Fe concentrations in plant shoots and roots were determined. Rhizospheric growth medium, sampled as the medium retained by roots after hand-shaken them on a table during $30 \mathrm{~s}$, was used to determine alkaline phosphomonoesterase, acid and alkaline phytase, T34 density and the concentration of low-molecular weight organic anions.

\section{Enzyme activity determination}

Phosphomonoesterase activity was determined as the amount of $\mathrm{p}$-nitrophenol released from $5 \mathrm{mM}$-nitrophenyl phosphate according to Tabatabai and Bremner (1969). Acid and alkaline phosphomonoesterase were determined at pH 5.5 and 9, respectively, in the Czapek media used for liquid cultivation of T34, and at pH 9 in the plant growth media. Phytase activity in the plant growth media and in the filtered Czapek media was determined by incubating the media in MES buffer at a volume ratio of $1: 1$ at $37^{\circ} \mathrm{C}$ for $60 \mathrm{~min}$. The final concentrations in the assay were $15 \mathrm{mM}$ MES and $2 \mathrm{mM}$ Ins6P - the latter was added as a substrate for the enzyme. The pH was 5.5 and 7.5 for acid and alkaline phytase, respectively. All solutions used were previously passed through a cellulose nitrate filter of $0.22 \mu \mathrm{m}$ pore size for sterilization. After incubation, the reaction was stopped by adding an identical volume of $10 \%$ trichloroacetic acid, and the suspensions centrifuged at $10000 \mathrm{~g}$ for $10 \mathrm{~min}$. The supernatants were used to determine molybdate reactive $P$ according to Murphy and Riley (1962), phytase activity was expressed in enzyme units ( $1 \mu \mathrm{mol}$ of molybdate reactive $\mathrm{P}$ released per $\mathrm{min}$ ) per $\mathrm{kg}$ of growth medium. $\mathrm{P}$ sorption on Fe oxides present in the plant growing media during hydrolysis of Ins6P was assessed by incubation in a $\mathrm{KH}_{2} \mathrm{PO}_{4} \mathrm{So}^{-}$ lution containing $4.2 \mathrm{mg} \mathrm{P} \mathrm{L}^{-1}$ in order to measure the fraction of phosphate recovered after the phytase activity assay (George et al. 2005). P concentrations after incubation of the growth media with Ins6P were corrected for the ratio of $\mathrm{P}$ recovery in the media. 


\section{Organic anion determination}

Organic anions were extracted from the plant growth media (Radersma and Grierson 2004) by using water at a 1:1 ratio with the sand and shaking in a end-over-end shaker at $4 \mathrm{~Hz}$ for $1.5 \mathrm{~h}$. Then, the suspensions were centrifuged at $10000 \mathrm{~g}$ for $10 \mathrm{~min}$ and the supernatants passed through filters of $0.45 \mu \mathrm{m}$ pore size. With the Czapek media, the filtrates obtained from the $0.22 \mu \mathrm{m}$ filters were directly used for analysis. Organic anions were separated by high performance liquid chromatography on an HPLC Varian ProStar 410 instrument equipped with a C18 column from Varian ( $250 \mathrm{~mm} \times 34.6 \mathrm{~mm}, 8 \mu \mathrm{m}$ particle size) at $45^{\circ} \mathrm{C}$, using isocratic elution with $98 \% 25 \mathrm{mM} \mathrm{KH}_{2} \mathrm{PO}_{4}$ at $\mathrm{pH} 2$ and $2 \%$ methanol as carrier at a flow rate of $0.8 \mathrm{~mL} \mathrm{~min}^{-1}$ (injected volume $=20 \mu \mathrm{L}$ ). Organic anions were detected at $215 \mathrm{~nm}$, using a Varian 486335 photo-diode array detector. Individual stock standard solutions (acetic, oxalic, citric, malic, fumaric and succinic) were prepared from Sigma chemicals and combined to obtain a dilute working-strength standard.

\section{Plant analysis}

Plant shoots and roots were separated and their dry mass (DM) was determined after drying to constant weight in a forced-air oven at $65{ }^{\circ} \mathrm{C}$. Dried plant material was ground to pass through a $1 \mathrm{~mm}$ sieve prior to mineralization. An aliquot of $0.25 \mathrm{~g}$ was mineralized in porcelain crucibles in a furnace at $550{ }^{\circ} \mathrm{C}$ for $8 \mathrm{~h}$. Then, $10 \mathrm{~mL}$ of $1 \mathrm{M}$ $\mathrm{HCl}$ was used to dissolve ash and heated at $100^{\circ} \mathrm{C}$ for $15 \mathrm{~min}$, the digest being used to determine P and Fe. Phosphorus was determined according to Murphy and Riley (1962) and Fe by atomic absorption spectrometry. Certified plant material was also analysed in parallel to check for complete recovery of nutrients with this procedure. Seeds were also analysed with the same method in order to determine nutrient concentrations. Total uptake by plants was calculated as the total amount present in aerial parts and roots minus the total amount in seeds (Delgado and Torrent 1997).

\section{Determination of T34 density in growing media}

The density of T34 in the rhizospheric media after the experiments was determined by dilution plating, using the Trichoderma semi-selective medium of Chung and Hoitink (1990) according to Borrero et al. (2012). To this end, $5 \mathrm{~g}$ of growth medium was suspended in $90 \mathrm{~mL}$ of a $1 \mathrm{~g} \mathrm{~L}^{-1}$ pyrophosphate solution in water. The suspension was shaken and a 10 -fold dilution series from $10^{-1}$ to $10^{-4}$ was prepared with water agar $\left(1 \mathrm{~g} \mathrm{~L}^{-1}\right)$. Then, the suspensions were pipetted onto three plates per dilution. Colony forming units (CFU) were counted 7 days after plating and expressed as CFU mL $\mathrm{m}^{-1}$ growth medium. No CFU was detected in the treatments without T34 inoculation.

\section{Statistical analysis}

An analysis of variance was performed by using the General Linear Model procedure in Statgraphics Plus 5.1 (StatPoint, 2000) to identify the effects of the studied factors on the different variables measured in the experiments. Previously, data were checked for normal distribution and homoscedasticity by using the Kolmogorov-Smirnov test and Levenne test, respectively, as implemented with the previous software. Any data not passing either test required additional transformation (transformed data $=$ data $^{-b}$, being $b$ the slope of the relation between the logarithms of standard deviation and the logarithm of the mean for each treatment), which was effective to achieve ANOVA requirements. Each replication of the experiment with plants was considered a separate block in order to exclude the variation associated with repetition of the experiment (de Santiago et al. 2009). Only one factor ( $P$ source) was used in the analysis of variance of T34 CFU in the growing media because no CFU was detected in non-inoculated media. Means were compared via Tukey's test; by exception, when interactions between factors were significant, the main effects could not be assessed in a combined analysis, so it was impossible to compare factor means between treatments (de Santiago et al. 2013). A mean comparison for the combined effect of factors was performed when interaction was significant. Regressions and comparison between linear regressions were done by using the same model and software. 


\section{Results \\ Cultivation of T34 in liquid media}

Development of Trichoderma asperellum T34 in the liquid media, measured as the amount of biomass produced during incubation, differed depending on the P source; thus, it was higher with InsP6 and the more dilute $\mathrm{KH}_{2} \mathrm{PO}_{4}$ than with the other $\mathrm{P}$ sources (Table 1). Significant phosphomonoesterase and phytase activities were observed in all the liquid media, the $1 / 10 \mathrm{KH}_{2} \mathrm{PO}_{4}, \mathrm{PR}$ and Ins6P treatments exhibiting the highest phosphomonoesterase activity per gram of fungal biomass (Table 1). By contrast, phytase activity peaked with the full strenght $\mathrm{KH}_{2} \mathrm{PO}_{4}$ concentration but was not significantly different from that observed with InsP6 (Table 1). No significant differences in low-molecular weight organic anions, mostly oxalate ( $>99 \%$ of anions detected; beside oxalate, only trace amounts of citric acid were observed; results not shown) - between P sources were observed (Table 1). In all cases, $\mathrm{pH}$ was decreased relative to its initial value in the liquid culture media, and significant differences between $\mathrm{PR}$ and Ins6P were observed (Table 1). MRP concentrations decreased in the following sequence: $\mathrm{KH}_{2} \mathrm{PO}_{4}(0.23 \mathrm{~g}$ $\left.\mathrm{L}^{-1}\right)>\operatorname{Ins} 6 \mathrm{P}>1 / 10 \mathrm{KH}_{2} \mathrm{PO}_{4}\left(23 \mathrm{mg} \mathrm{L}^{-1}\right)>\mathrm{PR}$ (Table 1).

Table 1. Effect of various $\mathrm{P}$ sources on Trichoderma asperellum T34 biomass, molybdate reactive P (MRP) concentration and $\mathrm{pH}$, organic anions and enzyme production in liquid cultures of the fungus (Czapek media)

\begin{tabular}{|c|c|c|c|c|c|c|c|c|}
\hline \multirow[b]{2}{*}{$\begin{array}{l}\text { Source of } \\
\text { variation }\end{array}$} & \multirow[b]{2}{*}{ Biomass } & \multirow[b]{2}{*}{ MRP } & \multirow[b]{2}{*}{$\mathrm{pH}$} & \multicolumn{3}{|c|}{ Phosphomonoesterase } & \multicolumn{2}{|c|}{ Phytase } \\
\hline & & & & $\begin{array}{l}\text { Sum of } \\
\text { organic } \\
\text { anions }\end{array}$ & Acid & Alkaline & Acid & Alkaline \\
\hline P source ${ }^{a}$ & $\mathrm{~g} \mathrm{~L}^{-1}$ & $\mathrm{mg} \mathrm{L}^{-1}$ & & $\begin{array}{l}\mathrm{mmol} \\
\mathrm{g}^{-1} \\
\text { biomass }\end{array}$ & \multicolumn{2}{|c|}{$\mathrm{mg} \mathrm{pNP} \mathrm{h}^{-1} \mathrm{~g}^{-1}$ biomass } & \multicolumn{2}{|c|}{$\mathrm{EU} \mathrm{g}^{-1}$ biomass } \\
\hline Phosphate rock & $0.62 \pm 0.02 c$ & $3.1 \pm 1.4 \mathrm{~d}$ & $7.07 \pm 0.16 \mathrm{a}$ & $37 \pm 2$ & $3.7 \pm 0.1 \mathrm{a}$ & $4.3 \pm 0.8 a$ & $0.7 \pm 0.1 \mathrm{c}$ & $5.8 \pm 1.1 \mathrm{c}$ \\
\hline Ins6P & $1.54 \pm 0.1 \mathrm{a}$ & $159 \pm 4 b$ & $6.43 \pm 0.1 b$ & $36 \pm 7$ & $2.7 \pm 0.5 \mathrm{a}$ & $3.3 \pm 0.6 \mathrm{a}$ & $46.0 \pm 7.8 \mathrm{a}$ & $54.2 \pm 7.5 \mathrm{a}$ \\
\hline $1 / 10 \mathrm{KH}_{2} \mathrm{PO}_{4}$ & $1.82 \pm 0.34 \mathrm{a}$ & $17 \pm 0.5 c$ & $6.82 \pm 0.22 \mathrm{ab}$ & $46 \pm 8$ & $2.7 \pm 0.4 \mathrm{a}$ & $2.5 \pm 0.6 \mathrm{a}$ & $3.3 \pm 0.4 b$ & $10.6 \pm 1.2 \mathrm{~b}$ \\
\hline $\mathrm{KH}_{2} \mathrm{PO}_{4}$ & $0.98 \pm 0.1 c b$ & $227 \pm 1 \mathrm{a}$ & $6.72 \pm 0.06 a b$ & $36 \pm 7$ & $1.3 \pm 0.4 \mathrm{~b}$ & $0.2 \pm 0.1 b$ & $66.7 \pm 13.7 \mathrm{a}$ & $72.9 \pm 15.3 \mathrm{a}$ \\
\hline
\end{tabular}

Means \pm standard error, $n=3 ; a=$ all sources were supplied at a concentration of $0.23 \mathrm{~g} \mathrm{P} \mathrm{L} \mathrm{L}^{-1}$, by exception, $1 / 10$ Phosphate was applied at $23 \mathrm{mg} \mathrm{P} \mathrm{L}{ }^{-1}$; Ins6P = myo-inositol-6-hexakisphosphate; $\mathrm{PNP}=\mathrm{p}$-nitrophenol released; $\mathrm{EU}=$ enzyme units (in $\mu \mathrm{mol} \mathrm{P} \mathrm{min}^{-1}$ ) released; $\mathrm{MRP}=$ molybdate reactive $P$ as determined according to Murphy and Riley (1962); Means followed by different letters within a column are significantly different as per Tukey's test at $p<0.05$ for each factor

\section{Experiments with plants}

Plant DM was significantly lower with PR than with the other two sources $(p<0.001$; Tables 2 and 3$)$. The P concentration of shoots was lower with InsP6 $(p<0.01)$; however, the total P content of roots with this P source was not significantly different from that obtained with $\mathrm{KH}_{2} \mathrm{PO}_{4}$ and $\mathrm{PR}$ (Table 3). Phosphorus source also affected the Fe concentration of roots and total Fe content in shoots and roots (Tables 2 and 3), Ins6P decreasing the Fe concentration and total content of roots relative to $\mathrm{KH}_{2} \mathrm{PO}_{4}$ (Table 3). 


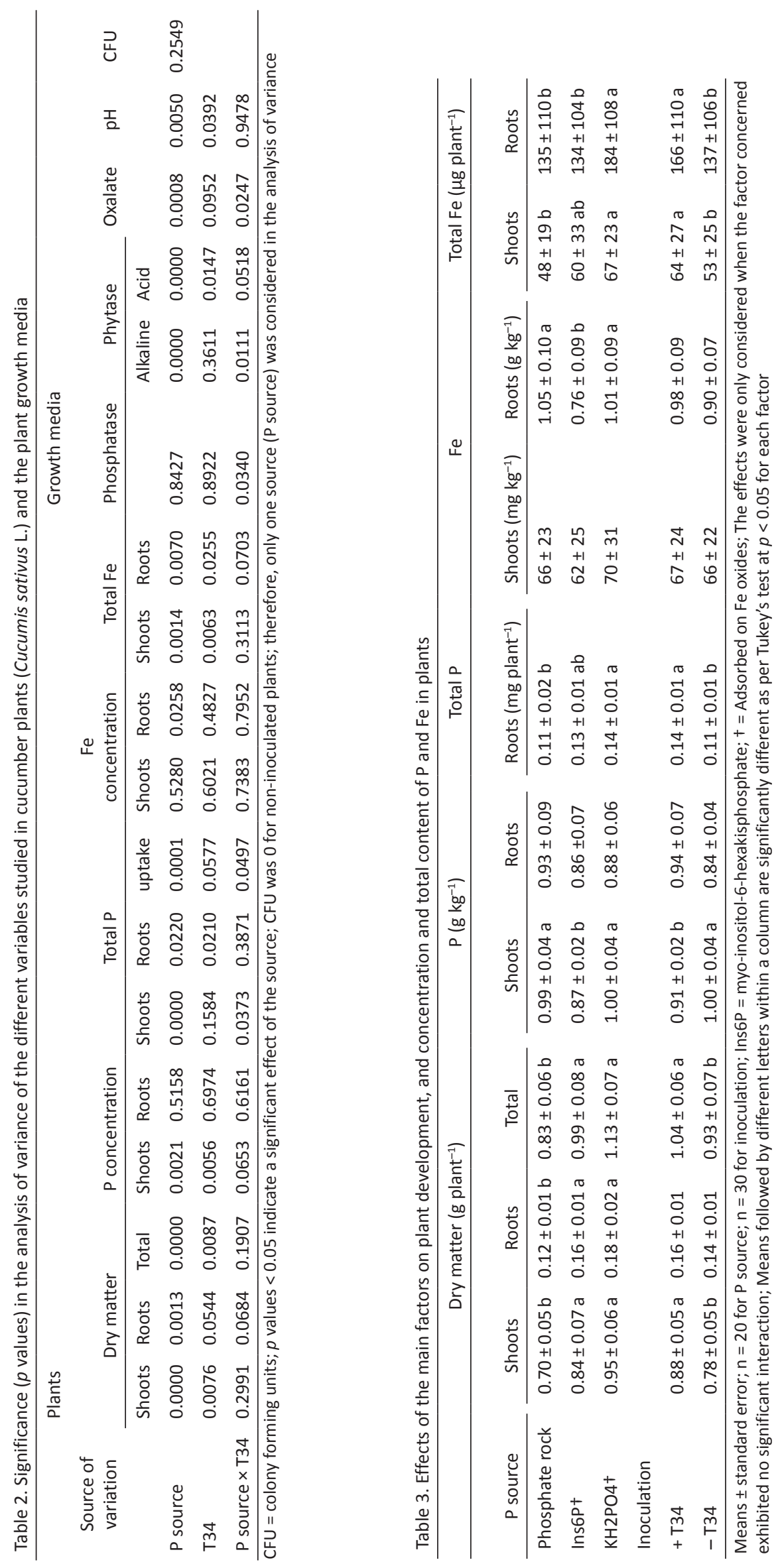


Acid phytase in the growth media after cultivation was greater with InsP6 than with the other P sources $(p<0.001$; Table 4). $\mathrm{pH}$ was also significantly affected by P source (Table 2$)$, with Ins6P leading to a lower value than PR ( $p<$ 0.01 ; Table 4).

Table 4. Effects of the main factors on properties of the plant growing media

\begin{tabular}{|c|c|c|c|c|}
\hline \multirow{2}{*}{$\begin{array}{l}\text { P source } \\
\text { Phosphate rock }\end{array}$} & \multicolumn{2}{|c|}{ Acid phytase (EU) $\mathrm{kg}^{-1}$} & \multirow{2}{*}{$\frac{\mathrm{pH}}{7.84 \pm 0.04 \mathrm{a}}$} & \multirow{2}{*}{$\frac{\text { CFU }}{9318 \pm 2335}$} \\
\hline & 0.5 & $\pm 0.1 \mathrm{~b}$ & & \\
\hline Ins6P† & 3.8 & $\pm 0.2 \mathrm{a}$ & $7.64 \pm 0.06 b$ & $9740 \pm 2482$ \\
\hline $\mathrm{KH} 2 \mathrm{PO} 4+$ & 1.2 & $\pm 0.3 \mathrm{~b}$ & $7.73 \pm 0.06 a b$ & $5155 \pm 1112$ \\
\hline \multicolumn{5}{|l|}{ Inoculation } \\
\hline$+\mathrm{T} 34$ & 2.1 & $\pm 0.4 \mathrm{a}$ & $7.69 \pm 0.04 b$ & \\
\hline$-\mathrm{T} 34$ & 1.6 & $\pm 0.4 \mathrm{~b}$ & $7.78 \pm 0.04 a$ & \\
\hline
\end{tabular}

$\mathrm{CFU}=$ colony forming units; $\mathrm{EU}=$ =enzyme units (amount of enzyme hydrolysing $1 \mu \mathrm{mol}$ of $\mathrm{P}$ in $1 \mathrm{~min}$ ); Ins6P = myo-inositol-6-hexakisphosphate; Means \pm standard error: $\mathrm{n}=20$ for $\mathrm{P}$ source; $\mathrm{n}=30$ for inoculation; $\dagger=$ Adsorbed on Fe oxides; The effects were only considered when the factor concerned exhibited no significant interaction; Means followed by different letters in a column were significantly different as per Tukey's test at; $p<0.05$ for each factor

Inoculation with T34 increased DM $(p<0.01)$, total content of Fe in shoots $(p<0.01)$, and total contents of P and Fe in roots $(p<0.05)$ (Tables 2 and 3). Total P uptake was linearly related to total Fe uptake. However, linear regression had significantly lower slopes $(p<0.05)$ with T34 than without it (Fig. 1$)$, thus revealing that P uptake was less markedly dependent on Fe uptake in the presence of T34 than in its absence.

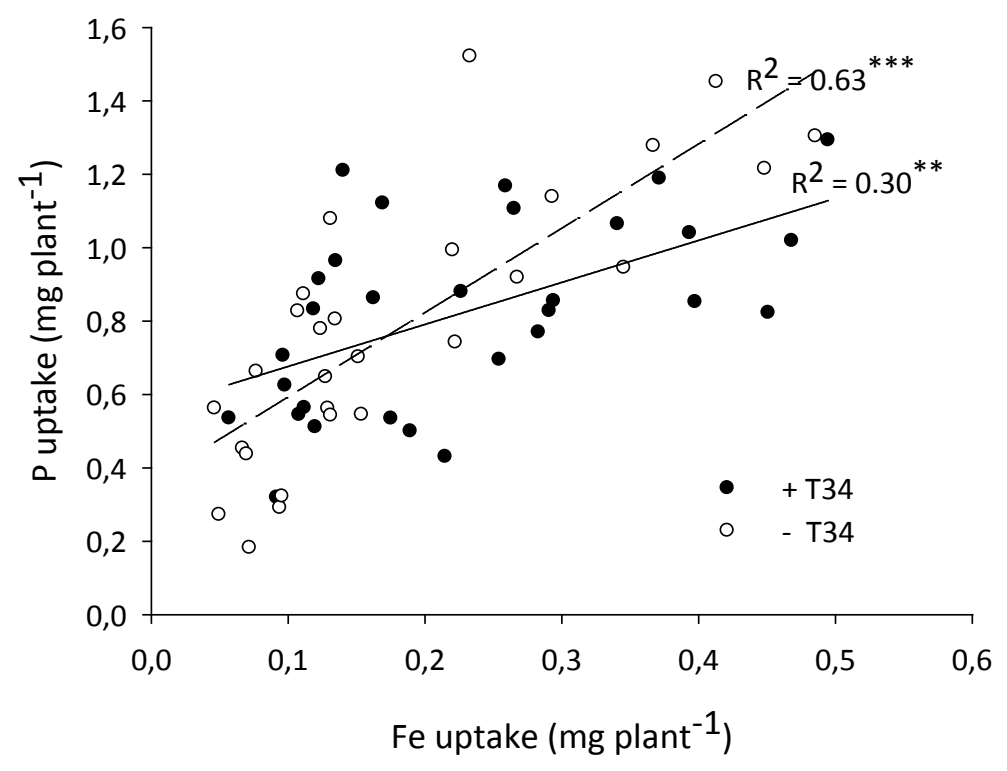

Fig. 1. Relationships between total $P$ uptake and total Fe uptake by cucumber plants. The dotted line represents the linear regression for plants without T34 inoculation $(Y=0.36+2.3 \mathrm{X})$ and the solid line that for inoculated plants $(\mathrm{Y}=0.56+1.15 \mathrm{X})$. The intercept and slope of both regression lines were significantly different at $p<0.05 * *$. 
T34 increased acid phytase activity and decreased $\mathrm{pH}$ after cultivation in the growth media $(p<0.05$, in both cases; Tables 2 and 4). The effect of T34 on alkaline phytase, total content of P in aerial parts and total P uptake by plants was dependent on P source as suggested by the significant interaction between both factors $(p<0.05$; Table 2$)$. With Ins6P, T34 led to a P uptake and total $\mathrm{P}$ content of aerial parts not significantly different from those obtained with $\mathrm{KH}_{2} \mathrm{PO}_{4}(\mathrm{Table} 5)$.

Table 5. Effect of the significant interactions between main factors on properties of the plant growth media and concentration and total content of $\mathrm{P}$ in plant

\begin{tabular}{|c|c|c|c|c|c|c|}
\hline P source & Inoculation & Total P uptake $\ddagger$ & Total P shoots & $\begin{array}{c}\text { Phospho- } \\
\text { monoesterase }\end{array}$ & $\begin{array}{l}\text { Alkaline } \\
\text { phytase }\end{array}$ & $\begin{array}{l}\text { Organic } \\
\text { anions }\end{array}$ \\
\hline & & \multicolumn{2}{|c|}{$\mathrm{mg} \mathrm{plant}^{-1}$} & $\mathrm{mg} \mathrm{pNP} \mathrm{kg}{ }^{-1} \mathrm{~h}^{-1}$ & $\mathrm{EU} \mathrm{kg}^{-1}$ & $\mathrm{mmol} \mathrm{kg}{ }^{-1}$ \\
\hline \multirow[t]{2}{*}{ Phosphate rock } & $+\mathrm{T} 34$ & $0.77 \pm 0.08 b c$ & $0.73 \pm 0.06 \mathrm{ab} A \S$ & $5.21 \pm 1.33$ & $2.0 \pm 0.1 \mathrm{a}$ & $47 \pm 15$ a $A$ \\
\hline & $-\mathrm{T} 34$ & $0.59 \pm 0.07 c$ & $0.62 \pm 0.07 \mathrm{~b} \mathrm{~B}$ & $4.02 \pm 0.08$ & $2.5 \pm 0.3 a$ & $32 \pm 10$ ab B \\
\hline \multirow[t]{2}{*}{ Ins6P† } & $+\mathrm{T} 34$ & $0.79 \pm 0.07 \mathrm{abc} A$ & $0.77 \pm 0.07 \mathrm{ab} A \S$ & $3.72 \pm 0.57$ & $1.5 \pm 0.07 \mathrm{~b} \mathrm{~A}$ & $6 \pm 2 c$ \\
\hline & $-\mathrm{T} 34$ & $0.54 \pm 0.10$ c B & $0.56 \pm 0.09 \mathrm{~b} \mathrm{~B}$ & $4.86 \pm 1.1$ & $1.2 \pm 0.07 \mathrm{c} \mathrm{B}$ & $16 \pm 5 a b$ \\
\hline \multirow[t]{2}{*}{$\mathrm{KH} 2 \mathrm{PO}_{4}{ }^{\dagger}$} & $+\mathrm{T} 34$ & $0.92 \pm 0.09 a b$ & $0.87 \pm 0.08 a$ & $4.11 \pm 0.83$ & $1.3 \pm 0.1 b c$ & $7 \pm 1$ bc $B$ \\
\hline & $-\mathrm{T} 34$ & $1.01 \pm 0.07 a$ & $0.98 \pm 0.06 a$ & $5.07 \pm 0.93$ & $1.2 \pm 0.09 c$ & $12 \pm 2 \mathrm{ab} A$ \\
\hline
\end{tabular}

Mean \pm standard error, $\mathrm{n}=10$; Ins6P = myo-inositol-6-hexakisphosphate; $\mathrm{EU}=$ enzymatic units (amount of enzyme hydrolysing 1 $\mu \mathrm{mol} \mathrm{P}$ in $1 \mathrm{~min}$ ); pNP = p-nitrophenol ; + = Adsorbed on Fe oxides; Means followed by a different lower case letter in a column were significantly different as per Tukey's test at $p<0.05$ for the six combinations of treatments; means followed by a different upper case letter in a column were significantly different as per Tukey's test at $p<0.05$ for the same P source; $\S \mathrm{P}=0.0761$ and $p=0.0590$ for Ins6P and PR, respectively.; $¥=$ Estimated as total $P$ in aerial parts and roots minus $P$ present in seeds. Total $P$ in shoots was occasionally greater than total $\mathrm{P}$ uptake because $\mathrm{P}$ in seeds was not counted for $\mathrm{P}$ determination in aerial parts

Inoculation increased total $\mathrm{P}$ in aerial parts and total $\mathrm{P}$ uptake in the plants supplied with Ins6P (Table 5). In inoculated plant growth media, total $\mathrm{P}$ uptake and $\mathrm{P}$ in shoots with PR was not significantly different from those with $\mathrm{KH}_{2} \mathrm{PO}_{4}$ (Table 5). Phosphomonoesterase and organic anions in the growing media after cultivation were also affected by T34, but an opposite trend with PR vs other two P sources was observed explaining the significant interaction in both variables (Table 2). Phosphomonoesterase activity was linearly related to root development, measured as DM $\left(R^{2}=0.32 ; p<0.001, n=60\right)$, and to CFU of T34 in the media $\left(R^{2}=0.34 ; p<0.05, n=30 ;\right.$ noninoculated pots excluded). The contents in organic anions - oxalate accounted for the only one detected- were decreased by $\mathrm{T} 34$ with $\mathrm{KH}_{2} \mathrm{PO}_{4}$ and Ins6P, which were the two $\mathrm{P}$ sources leading to the lowest concentrations of organic anions in the growth media, meanwhile the opposite effect was observed with PR (Table 5).

\section{Discussion}

\section{Effect of T34 on plant development and nutrient uptake}

Trichoderma asperellum T34 increased the total content of $\mathrm{P}$ in roots of cucumber (Tables 2 and 3 ) irrespective of the particular P form used to supply this nutrient; also, it enhanced total P uptake by plants when the phosphorus was supplied as Ins6P or PR (Tables 2 and 5). This reveals a favourable effect of the fungus on the use of not readily phytoavailable $\mathrm{P}$ forms (e.g., Ins6P, poorly soluble Ca phosphates) by plants. The improvement of $\mathrm{P}$ uptake by T34 is in agreement with previous works with other Trichoderma spp. which revealed their abilities for solubilising insoluble phosphates (Altomare et al. 1999, Rudresh et al. 2005). In addition to P, T34 increased the total content of Fe in shoots and roots of cucumber plants (Tables 2 and 3), which suggests improved Fe uptake in media with restricted availability of this nutrient by effect of their ferrihydrite concentration and pH (de Santiago et al. 2009).

The favourable effect of the fungus on development of cucumber plants measured as DM yield might be related to the improved P and Fe uptake observed with T34 in media with restricted availability of both nutrients (Table 3). Changes in phytohormone profile in plants (e.g. indole-3-acetic acid or 1-aminocyclopropane-1-carboxylic acid; Verma et al. 2007, Martínez-Medina et al. 2011) can also contribute to the effect of T34 increasing plant development. However, this effect seems improbable because there was not a significant increase in plant DM by T34 when the most effective $\mathrm{P}$ source $\left(\mathrm{KH}_{2} \mathrm{PO}_{4}\right)$ was only taken into account $(p=0.4668)$. T34 did not promoted positive effects on $\mathrm{P}(p=0.2403)$ or Fe uptake $(p=0.3943$ and $p=4012$ for total Fe in shoots and roots, respectively) by plants with $\mathrm{KH}_{2} \mathrm{PO}_{4}$. Thus, increased development by $\mathrm{T} 34$ seemed to be related to positive effects on P and Fe nutrition more clearly observed in plants supplied with PR and Ins6P. Although an increased uptake of other nutrients different from $\mathrm{P}$ and Fe by T34 is possible, which can also contribute to the effect of the 
fungi increasing plant development (Yedidia et al. 2001, de Santiago et al. 2013), it seems unlikely because a sufficient supply of these nutrients is guaranteed through nutrient solution.

Iron mobilization strategies of plants and microorganisms involve the exudation of organic anions with Fe-complexation abilities (e.g., citrate) and acidification (Jones 1998, Marschner et al. 2011). This additionally contributes to increasing $\mathrm{P}$ availability to plants through desorption from oxides or dissolution of precipitated phosphates. Therefore, $\mathrm{P}$ uptake by plants may be related to Fe uptake by plants. However, the relationship between P uptake and Fe uptake was found to differ depending on whether the growth medium was inoculated with T34 (Fig. 1). This result suggests the involvement of different Fe and $\mathrm{P}$ release mechanisms when T34 is present in the growth medium, e.g. more specific mechanisms for Fe release by the fungus (e.g., siderophore production; (de Santiago et al. 2009), which can also provide more available Fe to plants with less P release from oxides.

\section{Enzymatic hydrolytic activities in growing media}

The improved P uptake by plants in T34-containing media where P was supplied in organic form (Ins6P) might be related to production of extracellular hydrolytic enzymes involved in the $\mathrm{P}$ cycle. This hydrolytic capacity was reflected in the phytase activity and MRP concentration observed in liquid pure cultures of T34 with Ins6P as the P source (Table 1) and in the increased acid phytase activity in plant growing media containing the fungus (Table 4). Also, alkaline phytase activity was increased by T34, but only when P was supplied to plant growth medium as Ins6P.

The effect of T34 on phosphomonoesterase activity in the plant growing media showed different trends depending on P source (significant interaction) and peaked with PR (Table 5). This P source was expected to lead to the lowest MRP concentrations in solution judging by the results with the liquid culture (Table 1). There is contribution of plants to such activity in the rhizosphere because $32 \%$ of all phosphomonoesterase activity was explained by root development, measured as DM; on the other hand, 34\% of this enzymatic activity was explained by T34 development, measured as CFU in the media. An increased phosphomonoesterase activity, which is related to the hydrolysis of monoester phosphates other than Ins6P, suggests the presence of an additional mechanism for T34 to facilitate $P$ nutrition by plants in soil. This activity is known to be involved in the turnover of organic $P$ in the rhizosphere (Turner and Haygarth 2005).

Phosphomonoesterase activity due to T34 was seemingly more strongly affected by the inorganic $\mathrm{P}$ concentration in solution than by $\mathrm{P}$ source. Thus, it was lower in the liquid T34 culture with the source leading to the highest MRP concentration in the medium (Table 1); by contrast, phytase activity was apparently more markedly affected by the dominant $P$ form present in the medium (Table 1). Phytase activities were greatest with Ins6P and full strength $\mathrm{KH}_{2} \mathrm{PO}_{4}$ in the T34 liquid cultures. It is known that phytase activity can increase at increased substrate concentration, but also at increased $\mathrm{KH}_{2} \mathrm{PO}_{4}$ in pure cultures (Chun et al. 2007). These results are consistent with those in the plant growing media, where acid phytase activities peaked with Ins6P (Table 4). Adsorption of fungal (acid) phytases on Fe oxides markedly reduces their activity (George et al. 2005). This activity is known to be increased by Ins6P by effect of adsorption of this P form on Fe oxides decreasing adsorption of phytase and increasing its catalytic activity over time as a result (Giaveno et al. 2010). This contributes to explain the increased acid phytase activity observed with Ins6P as $\mathrm{P}$ source in the plant growth media containing Fe oxides. Although inorganic $P$ is also adsorbed on Fe oxides, sorbent surfaces have a higher affinity for Ins6P than for inorganic $P$ (Berg and Joern 2006) as revealed in the present study by the much lower P concentration in equilibrium with InsP6 $\left(3 \mu \mathrm{g} \mathrm{L}^{-1}\right)$ than with phosphate $\left(1.5 \mathrm{mg} \mathrm{L}^{-1}\right)$ adsorbed on ferrihydrite. This accounts for the increased inhibition of acid phytase adsorption and hence the greater activity of this enzyme in solution observed with Ins6P relative to $\mathrm{KH}_{2} \mathrm{PO}_{4}$ (Table 4). An increased affinity of oxides for Ins6P relative to inorganic phosphate accounts for the decreased Fe accumulation in roots with the former $\mathrm{P}$ source compared to $\mathrm{KH}_{2} \mathrm{PO}_{4}$ since Ins6P inhibits adsorption of complexing organic compounds released by roots or T34 on Fe oxides, a requirement for efficient Fe release from Fe-rich particles (Borer et al. 2009).

\section{Acidification and organic anions in growth media}

The increased use of P from PR might be related to the acidification of the rhizosphere and/or the production of low-molecular weight organic anions facilitating dissolution of Ca phosphates (Reyes et al. 1999, Hariprasad and Niranjana 2009). These effects were observed in the pure culture of T34 (Table 1); also, acidification of the rhizosphere and increased concentration of organic anions with PR by T34 was observed in the plant growing media (Tables 4 and 5). 
Oxalate was the dominant organic anion in the plant growth media. This is unsurprising since oxalate is typically the dominant anion exuded by roots of cucumber (El-Baz et al. 2004) and other plants (Jones 1998, Ström et al., 2005) under conditions of Fe or P deficiency. Furthermore, microbial degradation in the rhizosphere can have a lesser effect on oxalate than on other organic anions (Ström et al. 2001). A much higher organic anion concentration was found with PR than with Ins6P or $\mathrm{KH}_{2} \mathrm{PO}_{4}$ (Table 5). In spite of the organic anion production by $\mathrm{T} 34$ observed in the pure liquid culture (Table 1), the effect of the fungus was not always positive in plant growth media. In these media, T34 increased the concentration of organic anions with PR, thus contributing to dissolve PR, but decreased it with Ins6P and $\mathrm{KH}_{2} \mathrm{PO}_{4}$ as revealed by the significant interaction between both factors (Tables 2 and 5). This can be explained at least in part by the production of organic anions by plants. Plants and T34 seemingly increased organic anions concentrations to a greater extent with PR than with other P sources because this strategy is essential to dissolve sparingly soluble phosphates (Ström et al. 2005). With other P sources, T34 improves P uptake by plants through other mechanisms (e.g., hydrolytic activity with Ins6P); this can lead to a decreased exudation of organic anions by roots in order to mobilize P, which is highly costly in energetic terms (Ström et al. 2002, 2005).

\section{Conclusions}

Trichoderma asperellum T34 increased the total content in P of cucumber roots and enhanced total P uptake by plants when the phosphorus was supplied as Ins6P or PR. This was mainly explained by the production of extracellular hydrolytic enzymes involved in the $\mathrm{P}$ cycle, rhizosphere acidification, and increased organic anion concentration with T34. Although these results are promising for the potential usefulness of T34 for integration in biocontrol and $\mathrm{P}$ fertilization strategies, further research in soils and field conditions are still required.

\section{Acknowledgement}

This study was funded by the Spanish Ministry of Science and Innovation and the European Regional Development Fund of the European Union through the National Research, Development and Innovation Program (Plan Nacional I+d+i, AGL2011-29893-CO2-01).

\section{References}

Altomare, C., Norvell, W.A, Björkman, T. \& Harman, G.E. 1999. Solubilization of phosphates and micronutrients by the Plant-GrowthPromoting and Biocontrol Fungus Trichoderma harzianum Rifai 1295-22. Applied and Environmental Microbiology 65: 2926-2933.

Berg, A.S. \& Joern, B.C. 2006. Sorption dynamics of organic and inorganic phosphorus compounds in soil. Journal of Environmental Quality 35: 1855-1862.

Borer, P., Kraemer, S.M., Sulzberger, B., Hug, S.J. \& Kretzschmar, R. 2009. Photodissolution of lepidocrocite (c-FeOOH) in the presence of desferrioxamine B and aerobactin. Geochimica et Cosmochimica Acta 73: 4673-4687.

Borrero, C., Trillas, I., Delgado, A. \& Avilés, M. 2012. Effect of ammonium/nitrate ratio in nutrient solution on control of Fusarium wilt of tomato by Trichoderma asperellum T34. Plant Pathology 61: 132-139.

Browne, P., Rice, O., Miller, S.H., Burke, J., Dowling, D.N., Morrissey, J.P. \& O’Gara, F. 2009. Superior inorganic phosphate solubilization is linked to phylogeny within the Pseudomonas fluorescens complex. Applied Soil Ecology 43: 131-138.

Celi, L., Presta, M., Ajmore-Marsan, F. \& Barberis, E. 2001. Effects of pH and electrolytes on inositol hexaphosphate interaction with goethite. Soil Science Society of America Journal 65:753-760.

Chun, J.-A., Lee, W.-H., Han M.-O., Lee, J.-W., Yi, Y.-B., Park, G.-Y., Chung, G.-H. 2007. Optimization of abiotic factors for improved growth and extracellular production of recombinant fungal phytase in sesame hairy root cultures. Biotechnology and Bioprocess Engineering 12: 242-249.

Chung, Y.R. \& Hoitink, H.A.J. 1990. Interactions between thermophilic fungi and Trichoderma hamatum in suppression of Rhizoctonia damping off in a bark compost-amended container medium. Phytopathology 80: 73-77.

Cordell, D., Drangert, J.-O. \& White, S. 2009. The story of phosphorus: Global food security and food for thought. Global Environmental Change 19: 293-305.

de Santiago, A., García-López, A.M., Quintero, J.M., Avilés, M. \& Delgado, A. 2013. Effect of Trichoderma asperellum strain T34 and glucose addition on iron nutrition in cucumber grown on calcareous soils. Soil Biology and Biochemistry 57: 598-605.

de Santiago, A., Quintero, J.M., Avilés, M. \& Delgado, A. 2009. Effect of Trichoderma asperellum strain T34 on iron nutrition in white lupin. Soil Biology and Biochemistry 41: 2453-2459.

Delgado, A . \& Torrent, J. 1997. Phosphate-rich soils in the European Union: estimating total plant-available phosphorus. European Journal of Agronomy 6: 205-214.

Díaz-Espejo, A., Serrano, L. \& Toja, J. 1999. Changes in sediment phosphate composition of seasonal ponds during filling. Hydrobiologia 392: 21-28.

El-Baz, F.K., Mohamed, A.A., Aboul-Enein, A.M. \& Salama, Z.A. 2004. Alteration in root exudates level during Fe-deficiency in two cucumber cultivars. International Journal of Agriculture and Biology 6: 45-48. 
George, T.S., Richardson, A.E. \& Simpson, R.J. 2005. Behaviour of plant-derived extracellular phytase upon addition to soil. Soil Biology and Biochemistry 37: 977-988.

Giaveno, C., Celi, L., Richardson, A.E., Simpsom, R.J. \& Barberis, E. 2010. Interaction of phytases with minerals and availability of substrate affect the hydrolysis of inositol phosphates. Soil Biology and Biochemistry 42: 491-498.

Gilbert, N. 2009. The disappearing nutrient. Nature 461: 716-718.

Hariprasad, P. \& Niranjana, S.R. 2009. Isolation and characterization of phosphate solubilising rhizobacteria to improve plant health of tomato. Plant and Soil 316: 13-24.

Howell, C.R. 2003. Mechanism employed by Trichoderma species in the biological control of plant diseases: The history and evolution of current concepts. Plant Disease 87: 4-10.

Jones, D.L. 1998. Organic acids in the rhizosphere-a critical review. Plant and Soil 205: 25-44.

Lemanceau, P., Bauer, P., Kraemer, S. \& Briat, J.F. 2009. Iron dynamics in the rhizosphere as a case study for analyzing interactions between soils, plants and microbes. Plant and Soil 321: 513-535.

Lindsay, W.L. 1979. Chemical equilibria in soils. New York: John Wiley and Sons. 449 p.

MacDonald, G.K., Bennett, E.M., Potter, P.A., Ramankutty, N. 2011. Agronomic phosphorus imbalances across the world's croplands. Proceedings of the National Academy of Sciences of the United States of America 108: 3086-3091.

Marschner, P., Crowley, D. \& Rengel, Z. 2011. Rhizosphere interactions between microorganisms and plants govern iron and phosphorus acquisition along the root axis - model and research methods. Soil Biology and Biochemistry 43: 883-894.

Marschner, P., Crowley, D. \& Yang, C.H. 2004. Development of specific rhizosphere bacterial communities in relation to plant species, nutrition and soil type. Plant and Soil 261: 199-208.

Martínez-Medina, A., Roldán, A., Albacete, A. \& Pascual, J.A. 2011. The interaction with arbuscular mycorrhizal fungi or Trichoderma harzianum alters the shoot hormonal profile in melon plants. Phytochemistry 72: 223-229.

Murphy, J. \& Riley, J.P. 1962. A modified single solution method for the determination of phosphate in natural waters. Analitica Chimica Acta 27: 31-36.

Patel, K.J., Singh, A.K., Nareshkumar, G. \& Archana, G. 2010. Organic-acid-producing, phytate-mineralizing rhizobacteria and their effect on growth of pigeon pea (Cajanus cajan). Applied Soil Ecology 44: 252-261.

Radersma, S. \& Grierson, P.F. 2004. Phosphorus mobilization in agroforestry: Organic anions, phosphatase activity and phosphorus fractions in the rhizosphere. Plant and Soil 259: 209-219.

Rahmatullah \& Torrent, J. 2000. Phosphorus dynamics and uptake by wheat in a model calcite-ferrihydrite system. Soil Science 165: 803-812.

Reyes, I., Bernier, L., Simard, R.R., Tanguay, P. \& Antoun, H. 1999. Characteristics of phosphate solubilization by an isolate of a tropical Penicillium rugulosum and two UV-induced mutants. FEMS Microbiology Ecology 28: 291-295.

Rudresh, D.L., Shivaprakash, M.K. \& Prasad, R.D. 2005. Tricalcium phosphate solubilizing abilities of Trichoderma spp. in relation to P uptake and growth and yield parameters of chickpea (Cicer arietinum L.). Canadian Journal of Microbiology 51: 217-22.

Ryan, J., Ibrikci, H., Delgado, A., Torrent, J., Sommer, R. \& Rashid, A. 2012. Significance of phosphorus for agriculture and environment in the West Asia and North Africa region. Advances in Agronomy 114: 91-153.

Saavedra, C. \& Delgado, A. 2005. Phosphorus fractions and release patterns in typical Mediterranean soils. Soil Science Society of America Journal 69: 607-615.

Saavedra, C., Velasco, J., Pajuelo, P., Perea, F. \& Delgado, A. 2007. Effects of tillage on phosphorus release potential in a Spanish Vertisol. Soil Science Society of America Journal 71: 56-63.

Sánchez-Alcalá, I., del Campillo, M.C., Torrent, J., Straub, K.L. \& Kraemer, S.M. 2011. Iron(III) reduction in anaerobically incubated suspensions of highly calcareous agricultural soils. Soil Science Society of America Journal 75: 2136-2146.

Schuster, A. \& Schmoll, M. 2010. Biology and biotechnology of Trichoderma. Applied Microbiology Biotechnology 87: 787-799.

Segarra, G., Casanova, E., Bellido, D., Odena, M.A., Oliveira, E. \& Trillas, I. 2007. Proteome, salicylic acid, and jasmonic acid changes in cucumber plants inoculated with Trichoderma asperellum strain T34. Proteomics 7: 3943-3952.

Singh, H. \& Reddy, M.S. 2011. Effect of inoculation with phosphate solubilizing fungus on growth and nutrient uptake of wheat and maize plants fertilized with rock phosphate in alkaline soils. European Journal of Soil Biology 47: 30-34.

StatPoint. 2000. Statgraphics Plus 5.1. Rockville, Maryland, USA.

Ström, L., Owen, A.G., Godbold, D.L. \& Jones, D.L. 2001. Organic acid §̧behaviour in a calcareous soil: sorption reactions and biodegradation rates. Soil Biology and Biochemistry 33: 2125-2133.

Ström, L., Owen, A.G., Godbold, D.L. \& Jones, D.L. 2002. Organic acid mediated P mobilization in the rhizosphere and uptake by maize roots. Soil Biology and Biochemistry 34: 703-710.

Ström, L., Owen, A.G., Godbold, D.L. \& Jones, D.L. 2005. Organic acid behaviour in a calcareous soil implications for rhizosphere nutrient cycling. Soil Biology and Biochemistry 37: 2046-2054.

Stutter, M.I., Shand, C.A., George, T.S., Blackwell, M.S.A., Bol, R., MacKay, R.L., Richardson, A.E., Condron, L.M., Turner, B.L. \& Haygarth, P.M. 2012. Recovering phosphorus from soil: a root solution? Environmental Science and Technology 46: 1977-1978.

Tabatabai, M.A. \& Bremner, J.M. 1969. Use of p-nitrophenyl phosphate for assay of soil phosphatase activity. Soil Biology and Biochemistry 1: 301-307.

Turner, B.L. \& Haygarth, P.M. 2005. Phosphatase activity in temperate pasture soils: Potential regulation of labile organic phosphorus turnover by phosphodiesterase activity. Science of the Total Environment 344: 27- 36.

Vassilev, N., Vassileva, M. \& Nikolaeva, I. 2006. Simultaneous P-solubilizing and biocontrol activity of microorganisms: potentials and future trends. Applied Microbiology Biotechnology 71: 137-144. 
Verma, M., Brar, S.K., Tiagy, R.D., Surampalli, R.Y. \& Valéro, J.R. 2007. Antagonistic fungi, Trichoderma spp.: Panoply of biological control. Biochemical Engineering Journal 37: 1-20.

Wang, Y., Hasbullah, Setia, R., Marschner, P. \& Zhang, F. 2012. Potential soil P mobilisation capacity-method development and comparison of rhizosphere soil from different crops. Plant and Soil 354: 259-267.

Yadav, R.L., Shukla, S.K., Suman, A. \& Singh, P.N. 2009. Trichoderma inoculation and trash management effects on soil microbial biomass, soil respiration, nutrient uptake and yield of ratoon sugarcane under subtropical conditions. Biology and Fertility of Soils 45: 461-468.

Yedidia, I., Srivastva, A.K., Kapulnik, Y. \& Chet, I. 2001. Effect of Trichoderma harzianum on microelement concentrations and increased growth of cucumber plants. Plant and Soil 235: 235-242. 